\title{
Structure and Chemical Durability of Lead Crystal Glass
}

Frédéric ANGELI ${ }^{a}$, Patrick JOLLIVET ${ }^{a}$, Thibault CHARPENTIER ${ }^{b}$, Maxime FOURNIER ${ }^{a}$, Stéphane GIN ${ }^{a}$

${ }^{a} C E A, D E N, D T C D$, SECM, F-30207 Bagnols-sur-Cèze, France

${ }^{b}$ NIMBE, CEA, CNRS, Université Paris-Saclay CEA Saclay 91191 Gif-sur-Yvette, France

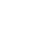

(1)

\section{Abstract}

Silicate glasses containing lead, also called lead crystal glasses, are commonly used as food product containers, in particular for alcoholic beverages. Lead's health hazards require major attention, which can first be investigated through the understanding of $\mathrm{Pb}$ release mechanisms in solution. The behavior of a commercial glass containing $10 \mathrm{~mol} \%$ of $\mathrm{PbO}$ (28 wt\%) was studied in a reference solution of $4 \%$ acetic acid at 22,40 and $700^{\circ}$ at ea rly and advanced stages of reaction. For the first time, high-resolution ${ }^{17} \mathrm{O}$ solid-state NMR was used to probe $\mathrm{Pb}$ in the pristine and altered crystal glass. Inserted into the vitreous structure between the network formers as $\mathrm{Si}-\mathrm{O}-\mathrm{Pb}$ bonds, $\mathrm{Pb}$ does not form $\mathrm{Pb}-\mathrm{O}-\mathrm{Pb}$ clusters which are expected to be more easily leached. A part of $\mathrm{K}$ is located near $\mathrm{Pb}$, forming $\mathrm{Si}-\mathrm{O}-(\mathrm{Pb}, \mathrm{K})$ mixing areas near the non-bridging oxygens. $\mathrm{Pb}$ is always released into the solution following a diffusion controlled process over various periods of time, at a rate between one and two orders of magnitude lower than the alkalis ( $\mathrm{K}$ and $\mathrm{Na}$ ). The preferential release of alkalis is followed by an in situ repolymerization of the silicate network. $\mathrm{Pb}$ is only depleted in the outermost part of the alteration layer. In the remaining part, it stays mainly surrounded by $\mathrm{Si}$ in a stable structural configuration similar to that of the pristine glass. 
INTRODUCTION

For thousands of years, lead has been used in the preparation of silicate glasses, in particular because it enables the temperature range of the glass-forming ability to be extended. It was widely used in various archeological artifacts, such as enamels and glazes ${ }^{1}$, but also in applications for optics, electronics ${ }^{2}$ or even in protection against irradiation ${ }^{3}$. Since the $17^{\text {th }}$ century, lead oxide has been added to alkali silicate to form a material called lead crystal, giving a high clarity and a characteristic sonority. Lead crystal has been regulated since 1969 in order to guarantee the quality of the material, based on density, refraction index and lead content criteria. Lead oxide must be at least $24 \mathrm{wt} \%$ to be designated as crystal.

Exposure to $\mathrm{Pb}$ is hazardous for the environment and for human health when it accumulates in the organism ${ }^{4,5}$. It is therefore of primary importance to understand the behavior of this element in manufactured articles throughout their conditions of use, particularly if they contain liquids intended for human consumption.

Numerous empirical studies have been carried out to examine the $\mathrm{Pb}$ leaching from glass or from glass ceramic in reactive environments, particularly in contact with different actual beverages or simple synthetic solutions such as acetic acid or nitric acid ${ }^{6-20}$. In commercial lead crystal glasses, it has generally been observed that the release of alkalis and $\mathrm{Pb}$ ions exhibited a square root time dependence through a diffusion process ${ }^{11,15,17,18}$. Their leaching kinetics usually increase with the temperature and with the acetic acid concentration ${ }^{17}$. During successive contacts, a decrease in the release of $\mathrm{Pb}$ has been observed with each additional solution contact ${ }^{16}$. However, there is a lack of mechanistic understanding able to account for and predict the $\mathrm{Pb}$ behavior, in relation with its structural evolution during leaching.

The structural arrangements coming from the incorporation of $\mathrm{Pb}$ into an alkali silicate network can significantly modify glass macroscopic properties, in particular its chemical durability ${ }^{10}$. For a low content, typically under $40 \mathrm{~mol} \%$ of $\mathrm{PbO}$, a major part of $\mathrm{Pb}$ may be assimilated to a modifier cation ${ }^{21}$, thus resembling an alkaline-earth type cation, forming ionic bonds with non-bridging oxygens (NBOs) ${ }^{22}$. When a large amount of $\mathrm{Pb}$ is added to reach an orthosilicate composition $(\mathrm{Pb} / \mathrm{Si}=2)$, oxygens are then linked to the metallic cations to form metal-bridging oxygen bonds $\mathrm{Pb}-\mathrm{O}-\mathrm{Pb}{ }^{23} . \mathrm{Pb}$ is then associated in trigonal pyramids connected by their edges to form interlinked $\mathrm{Pb}_{2} \mathrm{O}_{4}$ units ${ }^{24}$. In this case, $\mathrm{Pb}$ mainly takes a network former configuration, forming more covalent bonds with the oxygens ${ }^{21,25,26}$. For contents greater than $\sim 60$ mol\% of $\mathrm{PbO}, \mathrm{Pb}$ forms its own vitreous network ${ }^{27}$. $\mathrm{Pb}$ has the special feature of having ability to form a glass in a very wide range of concentration ${ }^{28}$, up to more than $80 \mathrm{~mol} \%$ of $\mathrm{PbO}$ for a rapidly-quenched glass ${ }^{23,27}$. When $\mathrm{Pb}$ acts as a network former cation, 
unlike most network formers, it does not provide to the glass a greater chemical durability: Pb clusters form extended lead-rich domains which are rapidly leached. There are percolation pathways between these domains, and the $\mathrm{Pb}$ release into solution strongly increases ${ }^{10}$. Generally, whatever the solution $\mathrm{pH}$, the release of $\mathrm{Pb}$ seems to decrease when its content is lower ${ }^{10,19,29}$.

The mechanisms of aqueous alteration of lead crystal glasses compared to their structural evolution during leaching had not been approached prior to this study. In order to give new insights into the understanding of $\mathrm{Pb}$ leaching of industrial glasses, a structural approach for the glass as well as its alteration layer is applied, together with the evolution of the elemental alteration profiles. Combined with the solution analyses under various experimental conditions, it enables the mechanisms involved to be better defined.

This work is focused on a commercial lead crystal glass containing $10 \mathrm{~mol} \%$ of $\mathrm{PbO}(28 \mathrm{wt} \%)$. Complementary experiments, which enabled various kinetics regimes to be reached, are conducted to simulate the short and long term behavior of the crystal glass. Hydrolysis mechanisms were investigated using dynamic experiments with high flow rate whereas interdiffusion mechanisms were highlighted from static experiments using saturated solutions with respect to amorphous silica (ionexchange processes are not affected by solution saturation). The experiments were carried out in $4 \%$ $(v / v)$ acetic acid solution, which is commonly used as a standard reference solution ${ }^{13,17,30}$. The local structure of pristine and altered materials was characterized by high-resolution solid-state Nuclear Magnetic Resonance (NMR) of silicon-29 and oxygen-17. Elemental depth profiling were monitored by Time-of-Flight Secondary Ion Mass Spectrometry (ToF-SIMS).

\section{EXPERIMENTAL}

\section{Materials.}

Two glasses were used for this study, the first being a commercial glass with the molar composition $77.1 \mathrm{SiO}_{2}-0.8 \mathrm{Na}_{2} \mathrm{O}-11.3 \mathrm{~K}_{2} \mathrm{O}-10.6 \mathrm{PbO}-0.2 \mathrm{Sb}_{2} \mathrm{O}_{3}$. A second glass was synthetized to be enriched in oxygen-17 (without Sb addition). $200 \mathrm{mg}$ of glass was prepared by sol-gel from a mixture of alkoxides hydrolyzed by $90 \%$ enriched water in ${ }^{17} \mathrm{O}{ }^{31}$. After reaction, this mixture was maintained at $1270{ }^{\circ} \mathrm{C}$ for 30 minutes under argon at mosphere in a Pt/Au crucible. ICP-OES analysis after acidic dissolution $\left(\mathrm{HCl}+\mathrm{HNO}_{3}+\mathrm{HF}\right)$ gave the molar composition: $80.7 \mathrm{SiO}_{2}-0.7 \mathrm{Na}_{2} \mathrm{O}-10.8 \mathrm{~K}_{2} \mathrm{O}-$ 7.9PbO.

\section{NMR.}

${ }^{29} \mathrm{Si}$ MAS NMR data were collected on a Bruker 300WB Avance I spectrometer operating at a magnetic field of 7.02 T. $\left(I=1 / 2\right.$, Larmor frequency $v_{0}=59.4 \mathrm{MHz}$ ). A Bruker $4 \mathrm{~mm}$ (outer diameter of the rotor) CPMAS Probe was used at a spinning frequency of $10 \mathrm{kHz}$. Silicon spectra were acquired 
using the CPMG sequence ${ }^{32}$, by typically accumulating 32 echoes with an echo delay of $4 \mathrm{~ms}$ between consecutive $180^{\circ}$ pulses. The echoes were th en summed up and Fourier transformed to obtain the spectra. A $20 \mathrm{~s}$ recycling time was used; checks were carried out that no spectral deformation was observed for longer recycling delays (up to $1200 \mathrm{~s}$ ). The spectra were referenced to an external tetrakis(trimethylsilyl)silane (TKS) sample, for which the highest intensity peak was situated at $-9.9 \mathrm{ppm}$ from that of TMS.

${ }^{17}$ O MAS NMR data were collected on a Bruker 500WB Avance II spectrometer operating at a magnetic field of $11.72 \mathrm{~T}\left(I=5 / 2\right.$, Larmor frequency $v_{0}=67.67 \mathrm{MHz}$,). A Bruker $4 \mathrm{~mm}$ CPMAS probe was used at a spinning frequency of $12.5 \mathrm{kHz}$. MAS NMR spectra were acquired using a rotor synchronized Hahn echo pulse sequence to minimize the baseline distortion, with soft $90^{\circ}$ and $180^{\circ}$ pulses (selective on the central transition, RF field $25 \mathrm{kHz}$ ), an echo delay of one rotation period and a recycle delay of $1 \mathrm{~s}$ (no change in lineshape was observed for longer delay). The MQMAS spectra were acquired with $64 t_{1}$ rotor-synchronized increments (of one rotation period) in the first dimension and a $1 \mathrm{~s}$ repetition time (4500 FIDs per $\mathrm{t}_{1}$ value were collected). The Z-filter pulse sequence ${ }^{33}$ was used with first and second pulse durations of $5 \mu \mathrm{s}$ and $2 \mu \mathrm{s}$, respectively (RF field $60 \mathrm{kHz}$ ), and a third $90^{\circ}$ soft pulse, selective on the central transition, of $3.5 \mu \mathrm{s}$ (RF field $\left.25 \mathrm{kHz}\right)^{34}$.

All data were processed and fitted using an in-house written software ${ }^{35}$.

\section{ToF-SIMS.}

Depth profiles were analyzed by ToF-SIMS IONTOF® TOF 5 using $\mathrm{O}_{2}{ }^{+}$sputtering beams analyzing a surface area of $60 \times 60 \mu \mathrm{m}^{2}$. Oxygen beam was tuned at $2 \mathrm{kV}, 500 \mathrm{nA}$. Elemental profiles were normalized to that of Si to avoid matrix effects.

\section{Leaching experiments.}

After crushing and sieving, the selected size fractions $(20-40$ and $63-125 \mu \mathrm{m})$ were washed by decantation in acetone and absolute ethanol to remove fine particles, according to Stokes' law. Then the specific surface areas of the glass powders were measured by krypton physical adsorption on the sample surface with the BET method on a Micromeritics ASAP 2020.

Forward dissolution rate $r_{0}$ was measured using a single-pass flow-through test (SPFT) at 22, 40 and $70{ }^{\circ} \mathrm{C}$. About $100 \mathrm{mg}$ of glass powder (63-125 $\mu \mathrm{m}$ particle size fraction) were placed into a column made of PTFE tube, through which $4 \%(\mathrm{~V} / \mathrm{v})$ acetic acid was passed at a flow rate between 0.2 and $0.6 \mathrm{~mL} / \mathrm{min}$ to avoid any feedback effect on the rate by glass constituent elements released into solution. The temperature of the leaching solution was monitored continuously at the reactor inlet and a maximum variation of $\pm 1{ }^{C}$ was allowed. The leachate was regularly sampled and the $\mathrm{Si}$ concentration was determined photometrically with a Merck Spectroquant test and a Cary Varian UV- 
visible spectrophotometer with a method analogous to ASTM D859-10. Taking into account the errors on the glass surface area and the Si concentration, the uncertainty on $r_{0}$ was about $10 \%$. The normalized mass losses, $N L_{i},\left(g \cdot \mathrm{m}^{-2}\right)$ were calculated with the equation (1):

$$
N L_{i}(t)=\sum_{j=1}^{j=n} \frac{1}{x_{i} \times S S A \times m}\left[\frac{\left(C(i)_{j}+C(i)_{j+1}\right)}{2} \times Q \times\left(t_{j+1}-t_{j}\right)\right]
$$

with $j$ the sampling, $C(I)_{j}$ the concentration of the element in the $j^{\text {th }}$ sampling, $Q$ the solution flow rate, $S S A$ the specific surface area of powder sample, $m$ the mass of glass, $x_{i}$ the weight fraction of element $i$ in the glass, and $t_{j+1}-t_{j}$ the time between two samplings.

Alteration in static conditions was measured in perfluoroalkoxy reactors (PFA) at 22, 40 and $70{ }^{\circ} \mathrm{C}$ in $4 \%(\mathrm{~V} / \mathrm{v})$ acetic acid solution. The mass of glass powder $(20-40 \mu \mathrm{m}$ and $63-125 \mu \mathrm{m}$ particle size fractions) was adjusted to have the desired glass-surface-area-to-solution-volume ratios (SA/V). The solutions were ultrafiltered (cutoff $10 \mathrm{kDa}$ ) and analyzed by ICP-OES.

$$
N L(i)_{t}=N L(i)_{t-1}+\frac{\left(C(i)_{t}-C(i)_{t-1}\right) \times V_{t}}{S S A \times m \times x_{i}}
$$

with $C(i)_{t}$ the concentration of the element $i$ in solution at time $t$, and $V_{t}$ the volume of solution sampling at time $t$.

The equivalent thickness of altered glass is given by:

$$
\operatorname{ETh}(i)=\frac{N L(i)}{\rho}
$$

$\rho$ is the glass density $\left(3.028 .10^{6} \mathrm{~kg} \cdot \mathrm{m}^{-3}\right)$. The uncertainties for $E T h(I)$ and the alteration rate $r=\mathrm{d} E T h(I) / \mathrm{d} t$ are of $10 \%$ and $30 \%$, respectively.

\section{RESULTS AND DISCUSSION}

\section{Glass structure}

\section{${ }^{29}$ Si MAS NMR.}

Two contributions were observed at $-94 \mathrm{ppm}$ and $-106 \mathrm{ppm}$ on the ${ }^{29} \mathrm{Si}$ MAS NMR spectra for pristine glass (Figure 1a), which correspond respectively to the $Q^{3}$ and $Q^{4}$ entities, in agreement with the data obtained on lead silica binary glasses ${ }^{36,37}$. The simulation of the ${ }^{29} \mathrm{Si}$ spectra gave a proportion of $59 \%$ of $Q^{3}$ and $41 \%$ of $Q^{4}$ units (see supplementary information, Figure $S 1$ ). The 
resulting number of NBOs is then 25.7\%. The calculation of the NBOs based on the glass composition, considering that two $\mathrm{NBO}$ are formed from $\mathrm{Na}_{2} \mathrm{O}, \mathrm{K}_{2} \mathrm{O}$ and $\mathrm{PbO}$ (without postulating free oxygen atoms) leads to a value of $25.6 \%$, very close to the experimental value.

\section{${ }^{17}$ O MAS NMR.}

The ${ }^{17} \mathrm{O}$ MAS spectrum of the pristine glass (Figure 1b) enables three contributions to be resolved. A wide line at the -20 to 50 ppm range with a characteristic second-order quadrupolar lineshape corresponds to the bridging oxygens Si-O-Si. Two narrower featureless peaks centered on 70 and $110 \mathrm{ppm}$ are related to the NBOs and may be attributed to $\mathrm{Si}-\mathrm{O}-\mathrm{K}$ and $\mathrm{Si}-\mathrm{O}-(\mathrm{Pb}, \mathrm{K})$, respectively (the latter corresponds to regions where $\mathrm{Pb}$ and $\mathrm{K}$ are mixed together but without forming $\mathrm{Pb}-\mathrm{O}-\mathrm{Pb}$ bonds). This attribution will be discussed hereafter from the MQMAS data.

\section{${ }^{17}$ O MQMAS NMR.}

The three contributions related to $\mathrm{Si}, \mathrm{K}$ and $\mathrm{Pb}$ are clearly separated on the experimental and simulated ${ }^{17} \mathrm{O}$ MQMAS spectra shown in Figure 2a. The simulated spectra, generated using a 3D distribution of the NMR parameters (taking into account the correlation effects between these parameters ${ }^{35}$ ), show very good agreement with the experimental spectra (Figure $\left.2 a\right)$. Figure $2 b$ shows the two-dimensional projection of the distribution of the NMR parameters, the isotropic chemical shift $\left(\delta_{\text {iso }}\right)$ and the quadrupolar coupling constant $\left(C_{Q}\right)$ extracted from the MQMAS spectra. Lee and Kim ${ }^{38}$ recently reported the structural evolution of binary lead silicate glasses from ${ }^{17} \mathrm{O} M Q M A S$ NMR for high $\mathrm{PbO}$ contents close to the orthosilicate composition ranging from $60 \mathrm{~mol} \%$ to $71 \mathrm{~mol} \%$. They clearly pointed out the presence $\mathrm{Pb}-\mathrm{O}-\mathrm{Pb}$ bonds which increased with $\mathrm{Pb}$ content at the expense of $\mathrm{Si}-$

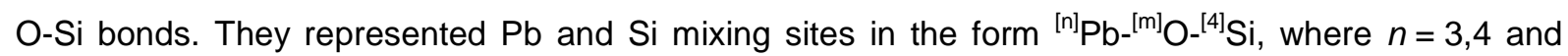
$m=2,3,4$. Under these conditions, the same oxygen atom could be involved in both $\mathrm{Pb}-\mathrm{O}-\mathrm{Si}$ and $\mathrm{Pb}$ $\mathrm{O}-\mathrm{Pb}$ bonds. The absence of $\mathrm{Pb}-\mathrm{O}-\mathrm{Pb}$ contribution (within the NMR detection limit) in our crystal glass suggests that $\mathrm{Pb}$ structural configuration may be fairly close to that of an alkaline-earth type network modifier.

Furthermore, the nature of the alkali cation at the origin of the NBO formation may modify the position of the ${ }^{17} \mathrm{O}$ line; a sodium disilicate decreases the NBO $\delta_{\text {iso }}$ by about 40 ppm compared to a potassium disilicate ${ }^{39}$. The position of the NBO site at around 75 ppm can be attributed here to Si-O$\mathrm{K}$, Si-O-Na being expected at around $40 \mathrm{ppm}^{35}$. Given the low $\mathrm{Na}$ content in the glass (below one percent) and the sensitivity of the MQMAS experiment, it remains challenging to observe Si-O-Na contribution on the ${ }^{17} \mathrm{O}$ MQMAS spectra.

A previous work carried out on a binary sodium silicate glass with a $77 \mathrm{~mol} \% \mathrm{SiO}_{2}$ content close to that studied here reported ${ }^{17} \mathrm{O}$ NMR parameters for the Si-O-Si site similar to those obtained 
for our lead glass ${ }^{35}$. Under these conditions, the addition of $\mathrm{Pb}$ to the glass does not seem to have a major effect on the Si-O-Si site geometry, either for the angular distributions (which influence the quadrupolar parameters ${ }^{40-42}$ ) or the $\mathrm{Si}-\mathrm{O}$ bond distances (which influence the isotropic chemical shift $\left.{ }^{43},{ }^{44}\right)$. In the binary lead silicate glasses studied by Lee and $\mathrm{Kim}{ }^{38}$, the $\mathrm{Si}-\mathrm{O}-\mathrm{Pb} \delta_{\text {iso }}$ was located around $151 \mathrm{ppm}$ and it slightly increased with $\mathrm{Pb}$ content. For our glass composition, the contribution related to $\mathrm{Pb}$ is close to $119 \mathrm{ppm}$ (see Table 1). The quantification of the three oxygen contributions enables the origin of this difference to be discussed.

By first assuming that the three ${ }^{17} \mathrm{O}$ sites revealed by the NMR spectra can be attributed to the contributions of Si-O-Si, Si-O-Pb and Si-O-K, Table 1 compares their proportions calculated from the crystal glass chemical composition and those obtained from the NMR data. It clearly appears that the quantity of $\mathrm{Si}-\mathrm{O}-\mathrm{Pb}(14 \%)$ is considerably greater than expected from the composition $(8.7 \%)$, unlike for Si-O-K where the quantity is lower ( $8 \%$ experimentally instead of the expected $12.7 \%$ ). This observation indicates that $\mathrm{Si}-\mathrm{O}-\mathrm{Pb}$ contribution does not only contain $\mathrm{Pb}$ and $\mathrm{Si}$ cations, but rather a mixing of $\mathrm{Pb}$ and $\mathrm{K}$, noted $\mathrm{Si}-\mathrm{O}-(\mathrm{Pb}, \mathrm{K})$, as had been previously observed for other types of cations having fairly close ionic radii ${ }^{45,46}$. Under these conditions, $\mathrm{Si}-\mathrm{O}-(\mathrm{Pb}, \mathrm{K})$ site would consist of $38 \%$ of $\mathrm{K}$ and $62 \%$ of $\mathrm{Pb}$. This effect thus explains the lower ${ }^{17} \mathrm{O} \delta_{\text {iso }}$ of the $\mathrm{Si}-\mathrm{O}-\mathrm{Pb}$ site in the glasses studied here compared to the binary glasses ${ }^{38}$; Si-O- $(\mathrm{Pb}, \mathrm{K})$ site at $119 \mathrm{ppm}$ is situated between $\mathrm{Si}-\mathrm{O}-\mathrm{K}$ at 75 ppm and $\mathrm{Si}-\mathrm{O}-\mathrm{Pb}$ at $151 \mathrm{ppm}$. Finally, it should be noted that the wider distribution of ${ }^{17} \mathrm{O} \delta_{\text {iso }}$ for Si-O$(\mathrm{Pb}, \mathrm{K})$ is probably the result of a greater structural and/or chemical disorder for this mixing site.

It is worth noting that by taking into account the difference in chemical shift between $\mathrm{Si}-\mathrm{O}-\mathrm{Pb}$ at $151 \mathrm{ppm}$ and Si-O-K at $75 \mathrm{ppm}$, weighting of the value obtained for Si-O-(Pb,K) at $119 \mathrm{ppm}$ would give a $\mathrm{K}$ quantity of $42 \%$, very close to the value directly deduced from the quantification of the MQMAS spectrum (38\%). It would therefore appear that ${ }^{17} \mathrm{O} \delta_{\text {iso }}$ of $\mathrm{Si}-\mathrm{O}-(\mathrm{Pb}, \mathrm{K})$ could provide information regarding the proportion of $\mathrm{K}$ mixing with $\mathrm{Pb}$ in the $\mathrm{NBO}$ environment.

\section{GLASS LEACHING.}

For the first set of experiments, the most favorable conditions for accessing silicate network hydrolysis mechanisms were chosen, based on a high renewal rate of a $4 \%(v / v)$ acetic acid solution. Figures $3(a, b, c)$ show the equivalent alteration thicknesses of $\mathrm{Na}, \mathrm{K}, \mathrm{Pb}$ and $\mathrm{Si}$ at 22,40 and $70{ }^{\circ} \mathrm{C}$ calculated from their normalized mass losses (Eq. (3)). The leaching of $\mathrm{Sb}$ (not shown) is very close to the Si. An activation energy for hydrolysis mechanisms in the forward dissolution rate regime, based on an Arrhenius law, is given from the $\mathrm{Si}$ release (Figure $3 \mathrm{~d}$ ). The linearity between the three temperatures shows the good agreement of the data, resulting in an activation energy of $38.7 \pm 1.7$ $\mathrm{kJ} . \mathrm{mol}^{-1}$. Within the temperature range studied $\left(22-70^{\circ} \mathrm{C}\right)$, the release of Si leading to the hydrolysis of the silicate network would thus seem to be controlled by the same mechanisms. It should be noted 
that the dissolution was significantly non-congruent; while the release of $\mathrm{Pb}$ and $\mathrm{Sb}$ were fairly close to the Si network former, $\mathrm{K}$ and $\mathrm{Na}$ were released much more rapidly. It is tricky to calculate unique activation energy for $\mathrm{Pb}, \mathrm{K}$ and $\mathrm{Na}$ as the non-linearity observed between the three temperatures strongly suggest that the leaching of these elements could not only resulted from network hydrolysis but also interdiffusion. At low temperature, the interdiffusion mechanism may probably favored whereas at higher temperature hydrolysis may be prevalent.

For the second set of experiments, a solution initially saturated with respect to amorphous silica ${ }^{47}$ was used in order to specifically focus on the interdiffusion mechanisms. It has recently been showed that there was no hydrolysis of Si under these conditions ${ }^{47}$. Figure $4(a, b, c)$ compares the normalized mass losses for $\mathrm{K}$ and $\mathrm{Pb}$ at 22, 40 and $70 \mathrm{C}$ as a function of the square root of time. The very low concentration of $\mathrm{Na}$ in the glass $(0.2 \mathrm{~mol} \%)$ made its measuring in solution only possible at $70^{\circ} \mathrm{C}$. It was then observed that it behaved like $\mathrm{K}$. Analogous behavior of $\mathrm{Na}$ and $\mathrm{K}$ is therefore probable at lower temperatures.

The resulting linear behavior suggests that the different cations are released in solution by a diffusive mechanism. The leaching of $\mathrm{Pb}$ was much lower than $\mathrm{K}$. The $\mathrm{Pb}$ behavior thus seems to be assimilated with multivalent elements, like the alkaline earths or the rare earth elements, which are leached much more slowly than the alkalis ${ }^{46}$. Fick's second law was used to derive the apparent diffusion coefficients at the interface between the glass and the solution by fitting the curves in Figures $4(a, b, c)$. The concentration in solution is then given by ${ }^{48}$ :

$$
C(i)=2 \frac{S S A \times m}{V} x_{i}\left(\frac{D_{i} \times t}{\pi}\right)^{\frac{1}{2}}
$$

where $C(l)$ is the concentration of element $i(i=\mathrm{K}$ or $\mathrm{Pb})$ in solution, $x_{i}$ is the concentration of $\mathrm{Pb}$ or $\mathrm{K}$ in the glass, $V$ the volume of the solution and $D_{i}$ the diffusion coefficient for $\mathrm{Pb}$ or $\mathrm{K}$.

Figure $4 d$ shows the evolution of the diffusion coefficients as a function of the temperature for $\mathrm{Pb}$ and $\mathrm{K}$. The resulting activation energies highlight a temperature dependence which is much lower for $\mathrm{Pb}$ than for $\mathrm{K}$, with values of $37.2 \pm 6.5 \mathrm{~kJ} \cdot \mathrm{mol}^{-1}$ and $72.2 \pm 7.6 \mathrm{KJ} \cdot \mathrm{mol}^{-1}$, respectively. At $22{ }^{\circ} \mathrm{C}$, a low diffusion coefficient of $(3.1 \pm 0.6) \cdot 10^{-22} \mathrm{~m}^{2} \cdot \mathrm{s}^{-1}$ is determined for $\mathrm{Pb}$. Depending on the temperature, $\mathrm{Pb}$ release into solution is between one and two orders of magnitude slower than the alkalis.

For higher $\mathrm{Pb}$ contents, from 25 to 70 mol\%, diffusion coefficients of more than four orders of magnitude higher were obtained in glasses altered in $0.1 \mathrm{~N}$ or $0.5 \mathrm{~N} \mathrm{HNO}_{3}$ solutions ${ }^{8,10}$. A percolation mechanism through the plumbate sub-network was observed. Binary lead silicate glasses with $\mathrm{PbO}$ starting from an approximately $33 \mathrm{~mol} \%$ content, had a diffusion coefficient increasing by about one order of magnitude when $\mathrm{PbO}$ content increased by $5 \%{ }^{10}$. One single composition was studied at a 
lower $\mathrm{Pb}$ content (25\%) below the percolation threshold; it showed less pronounced diffusion coefficient variations, of about $10^{-17} \mathrm{~m}^{2} . \mathrm{s}^{-1}$ suggesting a plateau. If this latter value is not taken into account, so if the data located within the percolation regime are extrapolated from our glass composition containing $10 \mathrm{~mol} \%$ of $\mathrm{PbO}$, a similar value $\left(10^{-22} \mathrm{~m}^{2} \cdot \mathrm{s}^{-1}\right)$ compared to that found in our study $\left(10^{-21} \mathrm{~m}^{2} \cdot \mathrm{s}^{-1}\right)$ is obtained. This value is far away from the plateau which was observed at approximately $10^{-17} \mathrm{~m}^{2} \cdot \mathrm{s}^{-1}$ for $25 \mathrm{~mol} \%$ of $\mathrm{PbO}$ (see supplementary information, Figure S2). Then, the sharp drop in the diffusion coefficient could be due to a second percolation threshold, which would explain the high difference between 10 and 25 mol\% of $\mathrm{PbO}$. The formation of $\mathrm{Pb}-\mathrm{O}-\mathrm{Pb}$ bonds with the increase in the $\mathrm{Pb}$ concentration, even if they do not yet constituted a plumbate sub-network, could lead to this first percolation threshold beyond which an increase in $\mathrm{Pb}$ release kinetics would occur.

Finally, in order to reach more advanced reaction progress, a third set of experiments were carried out in static conditions at different $S A / V$ ratios, varying from $10 \mathrm{~m}^{-1}$ to $10000 \mathrm{~m}^{-1}$. These long term experiments were conducted at $22{ }^{\circ} \mathrm{C}$ in $4 \%$ acet ic acid solution, without $\mathrm{Si}$ in the initial solution, for one year of leaching. Although there were four orders of magnitude between the surface ratios, Figure 5 reports small variations in the leaching of $\mathrm{Pb}$ and $\mathrm{K}$, showing that their releases remain controlled by interdiffusion at $22^{\circ} \mathrm{C}$. As expected from our previous experiments, $\mathrm{Pb}$ leaching is much lower than $\mathrm{K}$. The calculation of the retention factor for $\mathrm{Pb}$ compared to $\mathrm{K}\left(R F_{r \mathrm{~Pb})}=1-E T h(\mathrm{~Pb}) / E T h(\mathrm{~K})\right)$ gave similar values, with an average retention of $77 \%$ of $\mathrm{Pb}$ in the alteration layer. It may be noted that $\mathrm{Pb}$ concentrations in solution always remain much lower (by at least three orders of magnitude) than the solubility of lead acetate ${ }^{49}$. This confirms that the release of $\mathrm{Pb}$ is not controlled by its solubility limit, but rather by diffusion mechanisms.

\section{ALTERATION LAYER CHARACTERIZATION}

ToF-SIMS.

Figure 6 displays the elemental profiles obtained by ToF-SIMS on the glass altered at $70{ }^{\circ} \mathrm{C}$ in an acetic acid solution saturated with respect to amorphous silica after 1, 7 and 53 days. The progress of the alteration front on the glass surface is clearly visible over time. At the interface between the pristine glass and the alteration layer, the hydration front can be seen progressing, with a greater penetration of hydrogen compared to the alkalis depletion. The profiles for $\mathrm{Na}$ and $\mathrm{K}$ are very similar, in agreement with the concentrations measured in solution (Figure $4 \mathrm{c}$ ). $\mathrm{Pb}$ was clearly released to a lesser extent than the alkalis, and is only depleted on a thin external surface of the alteration layer. After 53 days, the depth of $\mathrm{Pb}$ depletion was fifteen times less than the total thickness of the alteration layer. The equivalent thicknesses for the different elements are in quite good agreement with the depths obtained from the ToF-SIMS profiles. The small differences which remained between the two methods could be explained because (i) calculation of ETh using the SSA of glass powder measured 
by $\mathrm{BET}$ underestimates $E T h^{50}$ (ii) a part of $\mathrm{K}(\sim 20-30 \%)$ is retained in the alteration layer and therefore not released in solution and (iii) it may exist variations in the abrasion rate of ToF-SIMS between the alteration layer external surface and the pristine glass, because of potentially different densities.

The elemental profiles obtained after one year of alteration at various SA/V ratios at $22{ }^{\circ} \mathrm{C}$ were very similar than the profiles obtained at $70^{\circ} \mathrm{C}$ for shorter periods. In particular, the three ar eas remain still observed: the hydration front, the alkalis depletion and the $\mathrm{Pb}$-depleted external surface which is still maintained for long term experiments (see supplementary information, Figure S3).

\section{MAS NMR.}

Small glass powders of a few microns were entirely altered under static conditions at $70^{\circ} \mathrm{C}$ in a $4 \%$ acetic acid solution containing oxygen-17 enriched water, in order to specifically probe the alteration layer by ${ }^{17} \mathrm{O}$ NMR. An experiment in oxygen-16 carried out in parallel and under the same $S A / V$ ratio conditions (but with a greater volume of solution), enabled the concentrations of elements in solution to be measured. This allowed the experiment to be stopped when all the glass had been altered, based on the release of $\mathrm{Na}$ in solution, and to estimate the alteration layer molar composition deduced from the solution analysis: $88.7 \mathrm{SiO}_{2}-2.5 \mathrm{~K}_{2} \mathrm{O}-7.9 \mathrm{PbO}-1.0 \mathrm{Sb}_{2} \mathrm{O}_{3}$.

Figure 1a compares the ${ }^{29} \mathrm{Si}$ MAS spectra for pristine glass and for glass altered in oxygen- 17 . An obvious reorganization within the alteration layer through a silicate network polymerization is clearly highlighted. Centered on the $Q^{2}-Q^{3}$ species in the pristine glass, a majority of the $\mathrm{Si}$ forms $\mathrm{Q}^{4}$ units in the alteration layer. Quantification of the NBOs was carried out based on the ${ }^{17} \mathrm{O}$ NMR data of Figure $1 \mathrm{~b}$ (reported in Table 1). The ${ }^{17} \mathrm{O}$ MAS spectrum clearly confirms that most of $\mathrm{K}$ had been released in solution whereas a significant part of $\mathrm{Pb}$ remained in the alteration layer. The line corresponding to the $\mathrm{Si}-\mathrm{O}-(\mathrm{Pb}, \mathrm{K})$ contribution, shifted towards the higher chemical shifts, becomes closer to the $\mathrm{Si}-\mathrm{O}-\mathrm{Pb}$ contribution observed in binary lead silicate glasses ${ }^{38}$, indicating a lower level of mixing between $\mathrm{Pb}$ and $\mathrm{K}$. This shows that in the $\mathrm{Si}-\mathrm{O}-(\mathrm{Pb}, \mathrm{K})$ site, $\mathrm{K}$ is preferentially extracted compared to $\mathrm{Pb}$.

Simulation of the ${ }^{17} \mathrm{O}$ MAS spectrum for altered glass was used to estimate the composition of the alteration layer from the various contributions. The following molar proportions were obtained: $93 \mathrm{SiO}_{2}-1 \mathrm{~K}_{2} \mathrm{O}-6 \mathrm{PbO}$ (there was no $\mathrm{Sb}$ in this glass), in quite good agreement with the mass balance found from the solution analysis $\left(88.7 \mathrm{SiO}_{2}-2.5 \mathrm{~K}_{2} \mathrm{O}-7.9 \mathrm{PbO}-1.0 \mathrm{Sb}_{2} \mathrm{O}_{3}\right)$. It should however be noted that the NMR indicates a higher $\mathrm{SiO}_{2}$ content (93\% instead of $\left.89 \%\right)$. This is related to the presence of $\mathrm{Si}-\mathrm{OH}$ sites which overlay the $\mathrm{Si}-\mathrm{O}-\mathrm{Si}$ contribution on the spectrum ${ }^{51}$. These sites were revealed from 2D heteronuclear correlations maps $\left({ }^{1} H \rightarrow{ }^{17} \mathrm{O}\right.$ HETCOR) (see supplementary information, Figure S4a). The NMR parameters considered for this site (Table 1) come from the work 
of Brunet et al. ${ }^{51}$. Simulation of the ${ }^{17} \mathrm{O}$ MAS spectrum gave $4 \%$ of Si-OH sites (see supplementary information, Figure S4b). The total number of NBOs of $11 \%$ is quite comparable to the number of NBOs deduced from the alteration layer composition (10.9\%). The repolymerization led to a decrease in the NBOs, dropping from $22 \%$ in the glass to $11 \%$ in the alteration layer (Table 1). A significant decrease can be noted for the widths of the NMR parameters distribution for the Si-O-Si site (related to higher Si-O-Si mean bond angles), as well as an increase in the quadrupolar coupling constant, closer to that in vitreous silicon ${ }^{52}$. These findings highlight the reorganization of the polymerized silicate network $\left(Q^{4}\right)$.

The behavior of $\mathrm{Pb}$ is closely related to the structural configuration it adopts, as much in the pristine glass as in the alteration layer. Homogeneously dispersed within the silicate network, the leaching of $\mathrm{Pb}$ is less favorable, and its release into solution is lower than the alkalis. When present at higher concentration than in the glass studied here, $\mathrm{Pb}$ may form clusters, and its leaching increases, probably as soon as it forms $\mathrm{Pb}-\mathrm{O}-\mathrm{Pb}$ bonds. For $45 \mathrm{wt} \%$ of $\mathrm{PbO}$ in a glass containing $\mathrm{Na}$ and $\mathrm{K}$, it has been reported that the alkalis and the lead were released at the same rate ${ }^{11}$. At higher concentration, there is a percolation of the $\mathrm{Pb}$ sub-network, which is preferentially highly released into solution. These high $\mathrm{Pb}$ contents seem to give rise to a surface enrichment in $\mathrm{Pb}{ }^{11,12}$. No such enrichment was observed for our $28 \mathrm{wt} \% \mathrm{PbO}$ glass; conversely, $\mathrm{Pb}$ is depleted in the outermost part of the alteration layer. In the remaining part, it stays surrounded by $\mathrm{Si}$ in a stable structural configuration similar to that of the pristine glass.

The data obtained from this work could enable parameters to be set for a simple predictive mechanistic model for lead leaching from commercial lead crystal glass. 


\section{REFERENCES}

1. Szaloki, I.; Braun, M.; Van Grieken, R., Quantitative characterisation of the leaching of lead and other elements from glazed surfaces of historical ceramics. J. Anal. At. Spectrom. 2000, 15, (7), 843-850.

2. Cohen, B. M.; Uhlmann, D. R.; Shaw, R. R., Optical and electrical properties of lead silicate glasses. Journal of Non-Crystalline Solids 1973, 12, (2), 177-188.

3. Barker, R. S.; McConkey, E. A.; Richards.Da, EFFECT OF GAMMA RADIATION ON OPTICAL ABSORPTION OF LEAD SILICATE GLASS. Phys. Chem. Glasses 1965, 6, (1), 24-\&.

4. Patrick, L., Lead toxicity, a review of the literature. Part 1: Exposure, evaluation, and treatment. Altern. Med. Rev. 2006, 11, (1), 2-22.

5. Graziano, J. H.; Blum, C. B.; Lolacono, N. J.; Slavkovich, V.; Manton, W. I.; Pond, S.; Moore, M. R., Human in vivo model for the determination of lead bioavailability using stable isotope dilution. Environ. Health Perspect. 1996, 104, (2), 176-179.

6. van Elteren, J. T.; Grilc, M.; Beeston, M. P.; Reig, M. S.; Grgic, I., An integrated experimentalmodeling approach to study the acid leaching behavior of lead from sub-micrometer lead silicate glass particles. J. Hazard. Mater. 2013, 262, 240-249.

7. Rahimi, R. A.; Sadrnezhaad, S. K., Effects of lon-Exchange and Hydrolysis Mechanisms on Lead Silicate Glass Corrosion. Corrosion 2012, 68, (9), 793-800.

8. Rahimi, R. A.; Sadrnezhaad, S. K.; Raisali, G.; Hamidi, A., Hydrolysis kinetics of lead silicate glass in acid solution. Journal of Nuclear Materials 2009, 389, (3), 427-431.

9. Sadrnezhaad, S. K.; Rahimi, R. A.; Raisali, G.; Foruzanfar, F., Mechanism of deleading of silicate glass by 0.5 N HNO3. Journal of Non-Crystalline Solids 2009, 355, (48-49), 2400-2404.

10. Mizuno, M.; Takahashi, M.; Takaishi, T.; Yoko, T., Leaching of lead and connectivity of plumbate networks in lead silicate glasses. J. Am. Ceram. Soc. 2005, 88, (10), 2908-2912.

11. Bertoncello, R.; Milanese, L.; Bouquillon, A.; Dran, J. C.; Mille, B.; Salomon, J., Leaching of lead silicate glasses in acid environment: compositional and structural changes. Appl. Phys. A-Mater. Sci. Process. 2004, 79, (2), 193-198.

12. Bonnet, C.; Bouquillon, A.; Turrell, S.; Deram, V.; Mille, B.; Salomon, J.; Thomassin, J. H.; Fiaud, C., Alteration of lead silicate glasses due to leaching in heated acid solutions. Journal of NonCrystalline Solids 2003, 323, (1-3), 214-220.

13. Guadagnino, E.; Gambaro, M.; Gramiccioni, L.; Denaro, M.; Feliciani, R.; Baldin, M.; Stacchini, P.; Giovannangeli, S.; Carelli, G.; Castellino, N.; Vinci, F., Estimation of lead intake from crystalware under conditions of consumer use. Food Addit. Contam. 2000, 17, (3), 205-218.

14. Guadagnino, E.; Verita, M.; Geotti-Bianchini, F.; Shallenberger, J.; Pantano, C. G., Surface analysis of $24 \%$ lead crystal glass articles: correlation with lead release. Glass Technol. 2002, 43, (2), 63-69.

15. Schultz-Munzenberg, C.; Meisel, W.; Gutlich, P., Changes of lead silicate glasses induced by leaching. Journal of Non-Crystalline Solids 1998, 238, (1-2), 83-90. 
16. Ahmed, A. A.; Youssof, I. M., Effect of repeated leaching on the release of lead and other cations from lead crystal glass (24\% PbO) by acid solutions and water. Glass Technol. 1997, 38, (5), 171-178.

17. Ahmed, A. A.; Youssof, I. M., Interaction between lead crystal glass (24 \% PbO) and acetic acid. Glastech. Ber.-Glass Sci. Technol. 1997, 70, (6), 173-185.

18. Ahmed, A. A.; Youssof, I. M., Reactions between water and lead crystal glass (24\% PbO). Glass Technol. 1997, 38, (1), 30-38.

19. Cailleteau, C.; Weigel, C.; Ledieu, A.; Barboux, P.; Devreux, F., On the effect of glass composition in the dissolution of glasses by water. Journal of Non-Crystalline Solids 2008, 354, (2-9), 117-123.

20. Graziano, J. H.; Blum, C., LEAD-EXPOSURE FROM LEAD CRYSTAL. Lancet 1991, 337, (8734), 141-142.

21. Kanunnikova, O. M.; Goncharov, O. Y., X-ray photoelectron analysis of lead-silicate glass structure. J. Appl. Spectrosc. 2009, 76, (2), 194-202.

22. Wang, P. W.; Zhang, L. P., Structural role of lead in lead silicate glasses derived from XPS spectra. Journal of Non-Crystalline Solids 1996, 194, (1-2), 129-134.

23. Alderman, O. L. G.; Hannon, A. C.; Holland, D.; Feller, S.; Lehr, G.; Vitale, A. J.; Hoppe, U.; von Zimmerman, M.; Watenphul, A., Lone-pair distribution and plumbite network formation in high lead silicate glass, 80PbO center dot 20SiO(2). Phys. Chem. Chem. Phys. 2013, 15, (22), 8506-8519.

24. Takaishi, T.; Takahashi, M.; Jin, J.; Uchino, T.; Yoko, T.; Takahashi, M., Structural study on $\mathrm{PbO}-\mathrm{SiO} 2$ glasses by X-ray and neutron diffraction and Si-29 MAS NMR measurements. J. Am. Ceram. Soc. 2005, 88, (6), 1591-1596.

25. Gee, I. A.; Holland, D.; McConville, C. F., Atomic environments in binary lead silicate and ternary alkali lead silicate glasses. Phys. Chem. Glasses 2001, 42, (6), 339-348.

26. Fayon, F.; Landron, C.; Sakurai, K.; Bessada, C.; Massiot, D., Pb2+ environment in lead silicate glasses probed by Pb-L-III edge XAFS and Pb-207 NMR. Journal of Non-Crystalline Solids 1999, 243, (1), 39-44.

27. Feller, S.; Lodden, G.; Riley, A.; Edwards, T.; Croskrey, J.; Schue, A.; Liss, D.; Stentz, D.; Blair, S.; Kelley, M.; Smith, G.; Singleton, S.; Affatigato, M.; Holland, D.; Smith, M. E.; Kamitsos, E. I.; Varsamis, C. P. E.; loannou, E., A multispectroscopic structural study of lead silicate glasses over an extended range of compositions. Journal of Non-Crystalline Solids 2010, 356, (6-8), 304-313.

28. Fajans, K.; Kreidl, N. J., STABILITY OF LEAD GLASSES AND POLARIZATION OF IONS. J. Am. Ceram. Soc. 1948, 31, (4), 105-114.

29. Carmona, N.; Garcia-Heras, M.; Gil, C.; Villegas, M. A., Chemical degradation of glasses under simulated marine medium. Mater. Chem. Phys. 2005, 94, (1), 92-102.

30. Hight, S. C., Lead migration from lead crystal wine glasses. Food Addit. Contam. 1996, 13, (7), 747-765.

31. Angeli, F.; Charpentier, T.; Gaillard, M.; Jollivet, P., Influence of zirconium on the structure of pristine and leached soda-lime borosilicate glasses: Towards a quantitative approach by 0-17 MQMAS NMR. Journal of Non-Crystalline Solids 2008, 354, (31), 3713-3722. 
32. Larsen, F. H.; Farnan, I., Si-29 and O-17 (Q)CPMG-MAS solid-state NMR experiments as an optimum approach for half-integer nuclei having long T-1 relaxation times. Chem. Phys. Lett. 2002, 357, (5-6), 403-408.

33. Amoureux, J. P.; Fernandez, C.; Steuernagel, S., Z filtering in MQMAS NMR. J. Magn. Reson. Ser. A 1996, 123, (1), 116-118.

34. Fernandez, C.; Amoureux, J. P., 2D MULTIQUANTUM MAS-NMR SPECTROSCOPY OF AL27 IN ALUMINOPHOSPHATE MOLECULAR-SIEVES. Chem. Phys. Lett. 1995, 242, (4-5), 449-454.

35. Angeli, F.; Villain, O.; Schuller, S.; Ispas, S.; Charpentier, T., Insight into sodium silicate glass structural organization by multinuclear NMR combined with first-principles calculations. Geochim. Cosmochim. Acta 2011, 75, (9), 2453-2469.

36. Fayon, F.; Bessada, C.; Massiot, D.; Farnan, I.; Coutures, J. P., Si-29 and Pb-207 NMR study of local order in lead silicate glasses. Journal of Non-Crystalline Solids 1998, 232, 403-408.

37. Shrikhande, V. K.; Sudarsan, V.; Kothiyal, G. P.; Kulshreshtha, S. K., Si-29 MAS NMR and microhardness studies of some lead silicate glasses with and without modifiers. Journal of NonCrystalline Solids 2001, 283, (1-3), 18-26.

38. Lee, S. K.; Kim, E. J., Probing Metal-Bridging Oxygen and Configurational Disorder in Amorphous Lead Silicates: Insights from O-17 Solid-State Nuclear Magnetic Resonance. Journal of Physical Chemistry C 2015, 119, (1), 748-756.

39. Florian, P.; Vermillion, K. E.; Grandinetti, P. J.; Farnan, I.; Stebbins, J. F., Cation distribution in mixed alkali disilicate glasses. J. Am. Chem. Soc. 1996, 118, (14), 3493-3497.

40. Lee, S. K.; Stebbins, J. F., Effects of the degree of polymerization on the structure of sodium silicate and aluminosilicate glasses and melts: An O-17 NMR study. Geochim. Cosmochim. Acta 2009, 73, (4), 1109-1119.

41. Clark, T. M.; Grandinetti, P. J., Calculation of bridging oxygen O-17 quadrupolar coupling parameters in alkali silicates: A combined ab initio investigation. Solid State Nucl. Magn. Reson. 2005, 27, (4), 233-241.

42. Clark, T. M.; Grandinetti, P. J.; Florian, P.; Stebbins, J. F., An O-17 NMR investigation of crystalline sodium metasilicate: Implications for the determination of local structure in alkali silicates. Journal of Physical Chemistry B 2001, 105, (49), 12257-12265.

43. Ashbrook, S. E.; Berry, A. J.; Wimperis, S., O-17 multiple-quantum MAS NMR study of highpressure hydrous magnesium silicates. J. Am. Chem. Soc. 2001, 123, (26), 6360-6366.

44. Ashbrook, S. E.; Berry, A. J.; Wimperis, S., O-17 multiple-quantum MAS NMR study of pyroxenes. Journal of Physical Chemistry B 2002, 106, (4), 773-778.

45. Lee, S. K.; Stebbins, J. F., Nature of cation mixing and ordering in Na-Ca silicate glasses and melts. Journal of Physical Chemistry B 2003, 107, (14), 3141-3148.

46. Angeli, F.; Charpentier, T.; Molieres, E.; Soleilhavoup, A.; Jollivet, P.; Gin, S., Influence of lanthanum on borosilicate glass structure: A multinuclear MAS and MQMAS NMR investigation. Journal of Non-Crystalline Solids 2013, 376, 189-198.

47. Gin, S.; Jollivet, P.; Fournier, M.; Angeli, F.; Frugier, P.; Charpentier, T., Origin and consequences of silicate glass passivation by surface layers. Nature Communications 2015, 6. 
48. Helebrant, A.; Pekarkova, I., Kinetics of glass corrosion in acid solutions. Ber. Bunsen-Ges. Phys. Chem. Chem. Phys. 1996, 100, (9), 1519-1522.

49. Apelblat, A.; Manzurola, E., Solubilities of manganese, cadmium, mercury and lead acetates in water from T=278.15 K to T=340.15 K. J. Chem. Thermodyn. 2001, 33, (2), 147-153.

50. Fournier, M.; UII, A.; Nicoleau, E.; Inagaki, Y.; Odorico, M.; Frugier, P.; Gin, S., Glass dissolution rate measurement and calculation revisited. Journal of Nuclear Materials 2016, 476, 140 154.

51. Brunet, F.; Charpentier, T.; Le Caer, S.; Renault, J. P., Solid-state NMR characterization of a controlled-pore glass and of the effects of electron irradiation. Solid State Nucl. Magn. Reson. 2008, 33, (1-2), 1-11.

52. Charpentier, T.; Kroll, P.; Mauri, F., First-Principles Nuclear Magnetic Resonance Structural Analysis of Vitreous Silica. Journal of Physical Chemistry C 2009, 113, (18), 7917-7929. 


\begin{tabular}{|c|c|c|c|c|c|}
\hline & & \multicolumn{2}{|c|}{${ }^{17} \mathrm{O}$ NMR Parameters } & \multirow{2}{*}{\begin{tabular}{|c|}
$\begin{array}{c}\text { Proportion } \\
\text { from } \\
\text { composition }\end{array}$ \\
$78 \%$
\end{tabular}} & \multirow{2}{*}{$\begin{array}{c}\begin{array}{c}\text { Proportion } \\
\text { from }{ }^{17} \mathrm{O} \\
\text { NMR }\end{array} \\
\\
78 \%\end{array}$} \\
\hline \multirow{3}{*}{$\begin{array}{l}\text { Pristine } \\
\text { glass }\end{array}$} & Si-O-Si & $\begin{array}{c}C_{Q}(M H z)-\left(\sigma_{C_{n}}\right) \\
\eta_{Q}-\left(\sigma_{\eta_{0}}\right)\end{array}$ & $\begin{array}{l}52.5(7.3) \\
4.8(0.3) \\
0.3(0.1) \\
\end{array}$ & & \\
\hline & $\mathrm{Si}-\mathrm{O}-(\mathrm{Pb}, \mathrm{K})$ & $\begin{array}{c}\delta_{i s o}(p p m)-\left(\sigma_{\delta_{\text {iso }}}\right) \\
C_{Q}(M H z)-\left(\sigma_{C_{n}}\right) \\
\eta_{Q}-\left(\sigma_{\eta_{0}}\right) \\
\end{array}$ & $\begin{array}{c}118.7(10.8) \\
3.1(0.5) \\
0.6(0.2)\end{array}$ & $\begin{array}{c}9 \% \\
(\mathrm{Si}-\mathrm{O}-\mathrm{Pb})\end{array}$ & $14 \%$ \\
\hline & Si-O-K & $\begin{array}{c}\delta_{i s o}(p p m)-\left(\sigma_{\delta_{i s o}}\right) \\
C_{Q}(M H z)-\left(\sigma_{C_{n}}\right) \\
\eta_{Q}-\left(\sigma_{\eta_{0}}\right)\end{array}$ & $\begin{array}{l}74.8(9.2) \\
2.2(0.5) \\
0.6(0.2)\end{array}$ & $13 \%$ & $8 \%$ \\
\hline \multirow{4}{*}{$\begin{array}{l}\text { Altered } \\
\text { glass }\end{array}$} & Si-O-Si & $\begin{array}{c}\delta_{i s o}(p p m)-\left(\sigma_{\delta_{i s o}}\right) \\
C_{Q}(M H z)-\left(\sigma_{C_{n}}\right) \\
\eta_{Q}-\left(\sigma_{\eta_{0}}\right) \\
\end{array}$ & $\begin{array}{l}42.0(5.0) \\
5.2(0.2) \\
0.2(0.1) \\
\end{array}$ & $89 \%$ & $89 \%$ \\
\hline & $\mathrm{Si}-\mathrm{O}-(\mathrm{Pb}, \mathrm{K})$ & $\begin{array}{c}\delta_{i s o}(p p m)-\left(\sigma_{\delta_{i s o}}\right) \\
C_{Q}(M H z)-\left(\sigma_{C_{n}}\right) \\
\eta_{Q}-\left(\sigma_{\eta_{0}}\right)\end{array}$ & $\begin{array}{c}130.0(12.0) \\
3.1(0.5) \\
0.6(0.2)\end{array}$ & $\begin{array}{c}8 \% \\
(\mathrm{Si}-\mathrm{O}-\mathrm{Pb})\end{array}$ & $6 \%$ \\
\hline & Si-O-K & $\begin{array}{c}\delta_{i s o}(p p m)-\left(\sigma_{\delta_{i s o}}\right) \\
C_{Q}(M H z)-\left(\sigma_{C_{o}}\right) \\
\eta_{Q}-\left(\sigma_{\eta_{0}}\right) \\
\end{array}$ & $\begin{array}{l}74.8(9.2) \\
2.2(0.5) \\
0.6(0.2)\end{array}$ & $3 \%$ & $1 \%$ \\
\hline & Si-O-H & $\begin{array}{c}\delta_{\text {iso }}(p p m)-\left(\sigma_{\delta_{\text {iso }}}\right) \\
C_{Q}(M H z)-\left(\sigma_{C_{n}}\right) \\
\eta_{O}-\left(\sigma_{\eta}\right)\end{array}$ & $\begin{array}{c}130.0(12.0) \\
3.1(0.5) \\
0.6(0.2)\end{array}$ & - & $4 \%$ \\
\hline
\end{tabular}

Table 1. ${ }^{17} \mathrm{O}$ NMR parameters obtained by fitting the ${ }^{17} \mathrm{O}$ MAS NMR data of pristine and altered glass (standard deviations, depending on the distribution of each parameter, are indicated in parentheses) using as constraints the parameters extracted from the MQMAS data. The $C_{Q}$ precision is $0.25 \mathrm{MHz}$ and $\delta_{\text {iso }}$ precision is $2 \mathrm{ppm}$. The site proportions, calculated from pristine and altered glass 
543

544 (a)

(b)
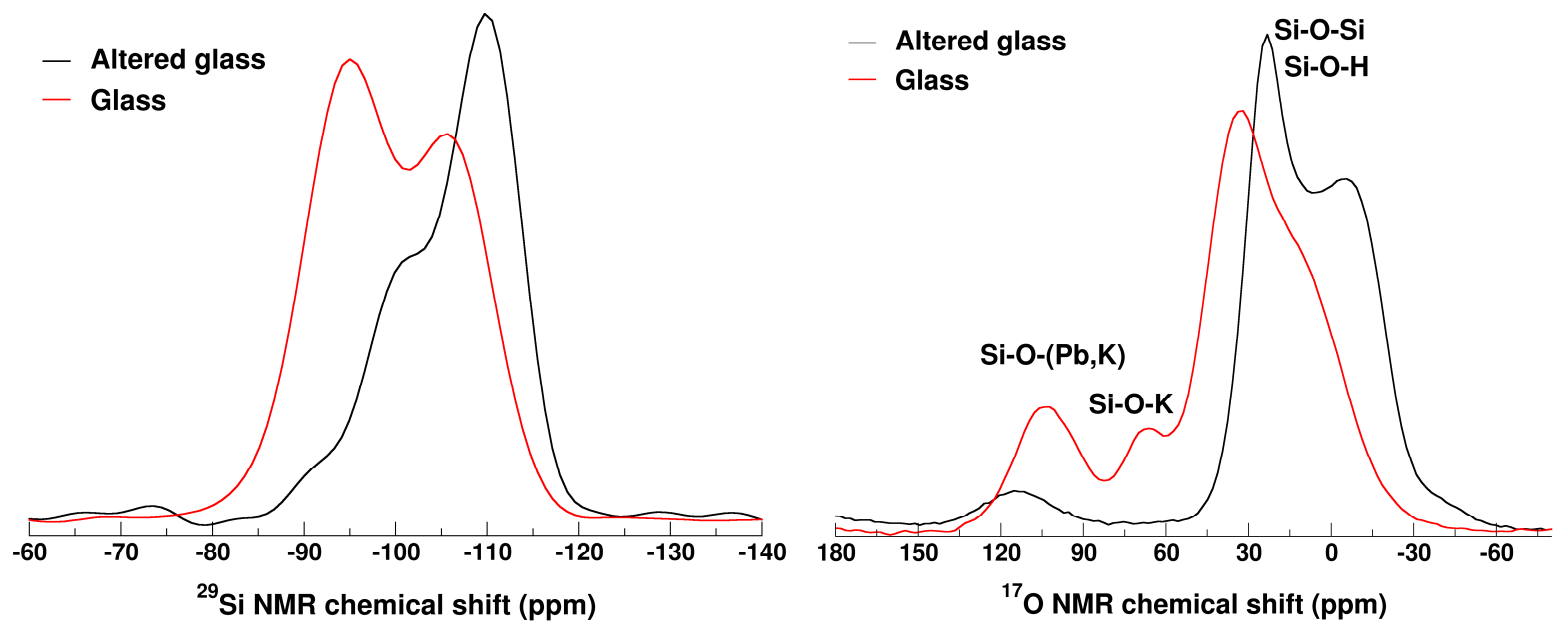

545

Figure 1. (a) ${ }^{29}$ Si MAS NMR and (b) ${ }^{17}$ O MAS NMR spectra of pristine and altered glass after 35 days 547 at $70{ }^{\circ}$ in acetic acid solution with oxygen-17 enriched water.

548

549

550

551

552

553

554 

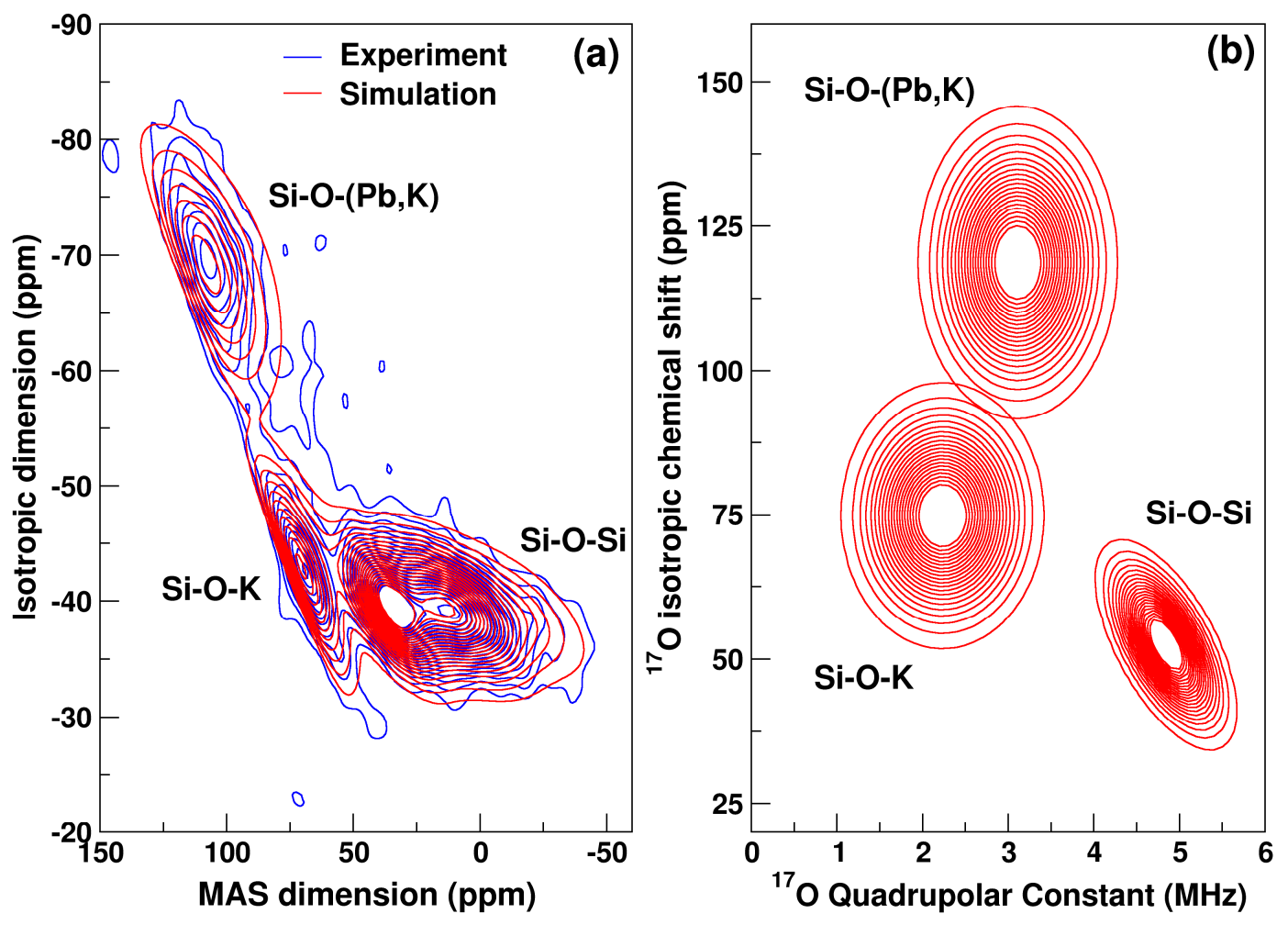

Figure 2. (a) Contour plots of the experimental and simulated ${ }^{17} O$ MQMAS spectra and (b) the twodimensional projection of the extracted ${ }^{17} \mathrm{O} N \mathrm{NM}$ parameter distributions $\delta_{\text {iso }}$ and $C_{Q}$. 
(a)

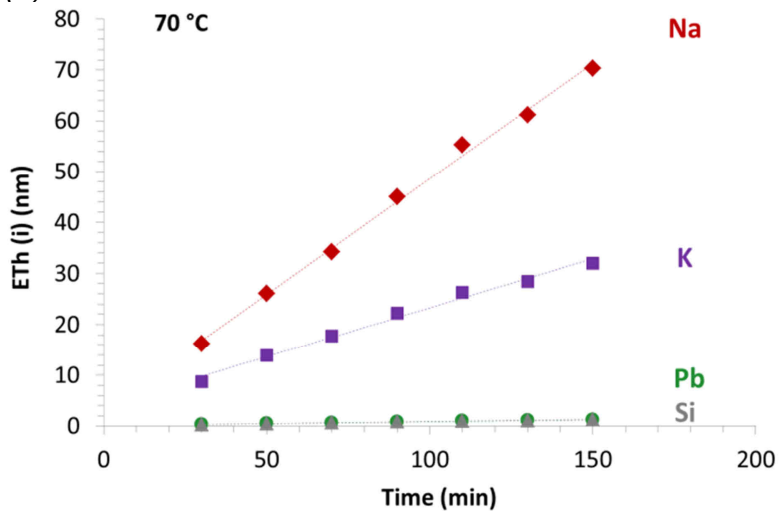

577

578

(c)

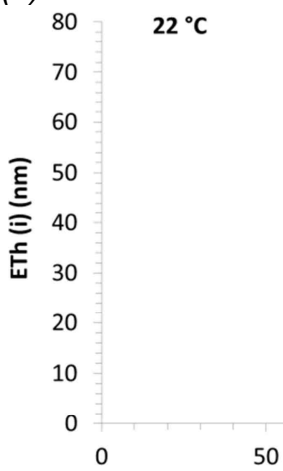

579

580

581

582

583

584

585

586

587

588

589

590

591

592

593

594

595

596

597 (b)

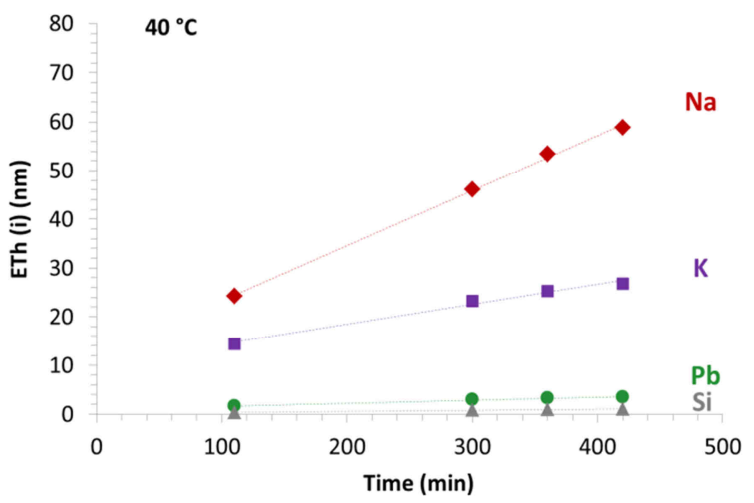

(d)

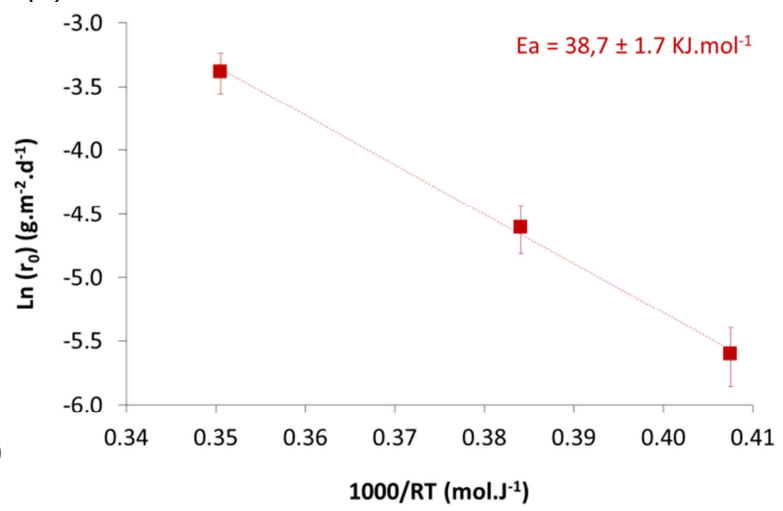

Figure 3. Equivalent thickness of altered glass calculated from the release of Si at $22{ }^{\circ} \mathrm{C}$ (a), $40^{\circ} \mathrm{C}$ (b) and $70{ }^{\circ} \mathrm{C}(\mathrm{c})$ in acetic acid, in forward dissolution rate regime. (d) Determination of the apparent activation energy for the alteration mechanisms in forward dissolution rate regime. Broken lines are simple visual aids. 

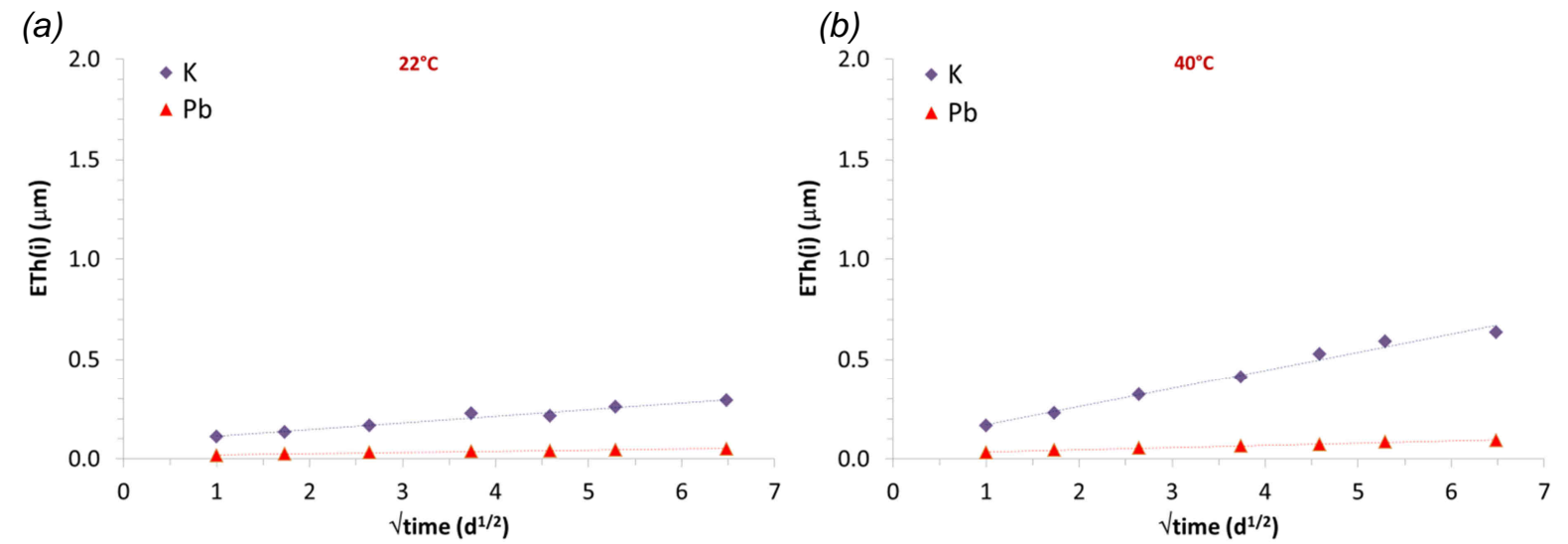

600

(c)

(d)
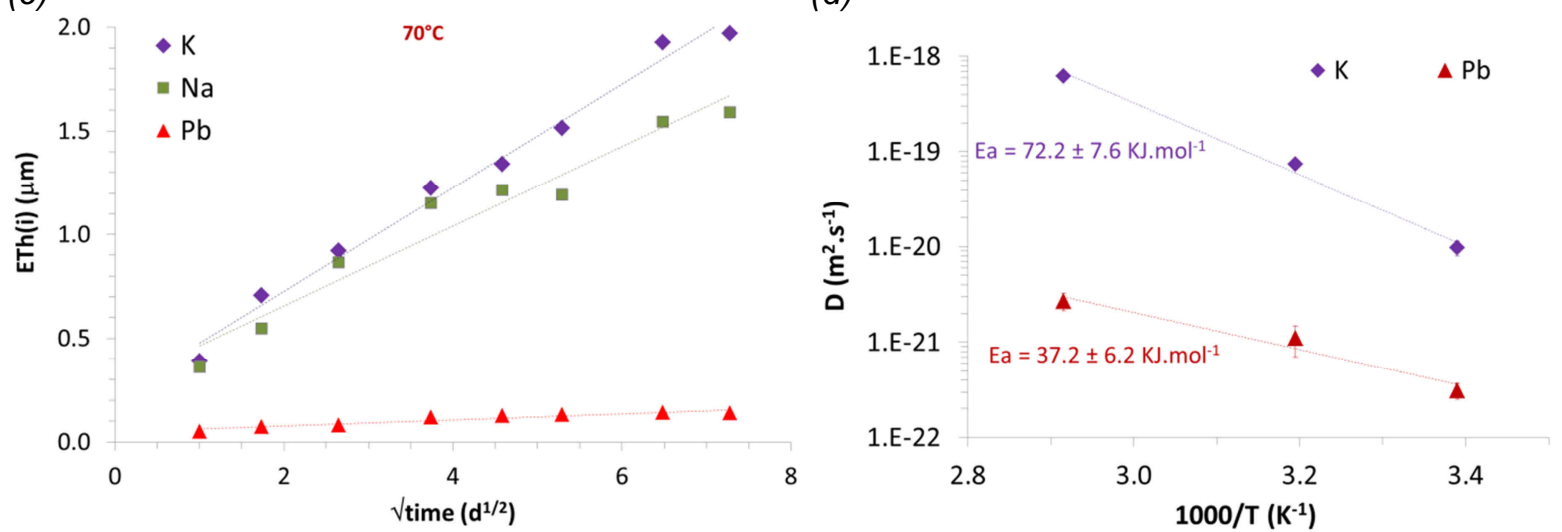

602

603

Figure 4. Equivalent thickness of altered glass calculated from the leaching of $\mathrm{Pb}$ and of $\mathrm{K}$ at $22 \mathrm{C}$

605

(a), 40C (b) and $700^{\circ}$ (b) in acetic acid solution, in a solution initially saturated with respect to amorphous silica. (d) Representation of the diffusion coefficients depending on the temperature. The 
623
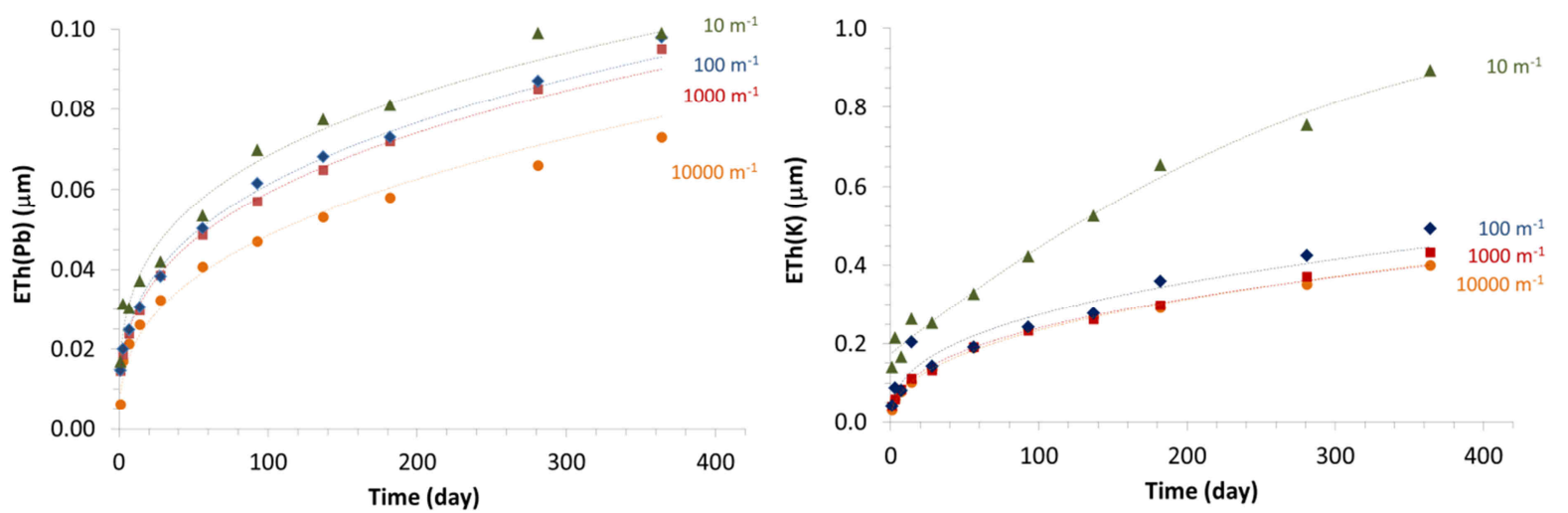

625

626 Figure 5. Equivalent thickness of altered glass calculated from the release of (a) $\mathrm{Pb}$ and (b) $\mathrm{K}$ at $22 \mathrm{C}$ 627 in acetic acid solution for different SA/V ratios $\left(10,100,1000\right.$ and $\left.10000 \mathrm{~m}^{-1}\right)$. Broken lines are simple 628 visual aids.

629 

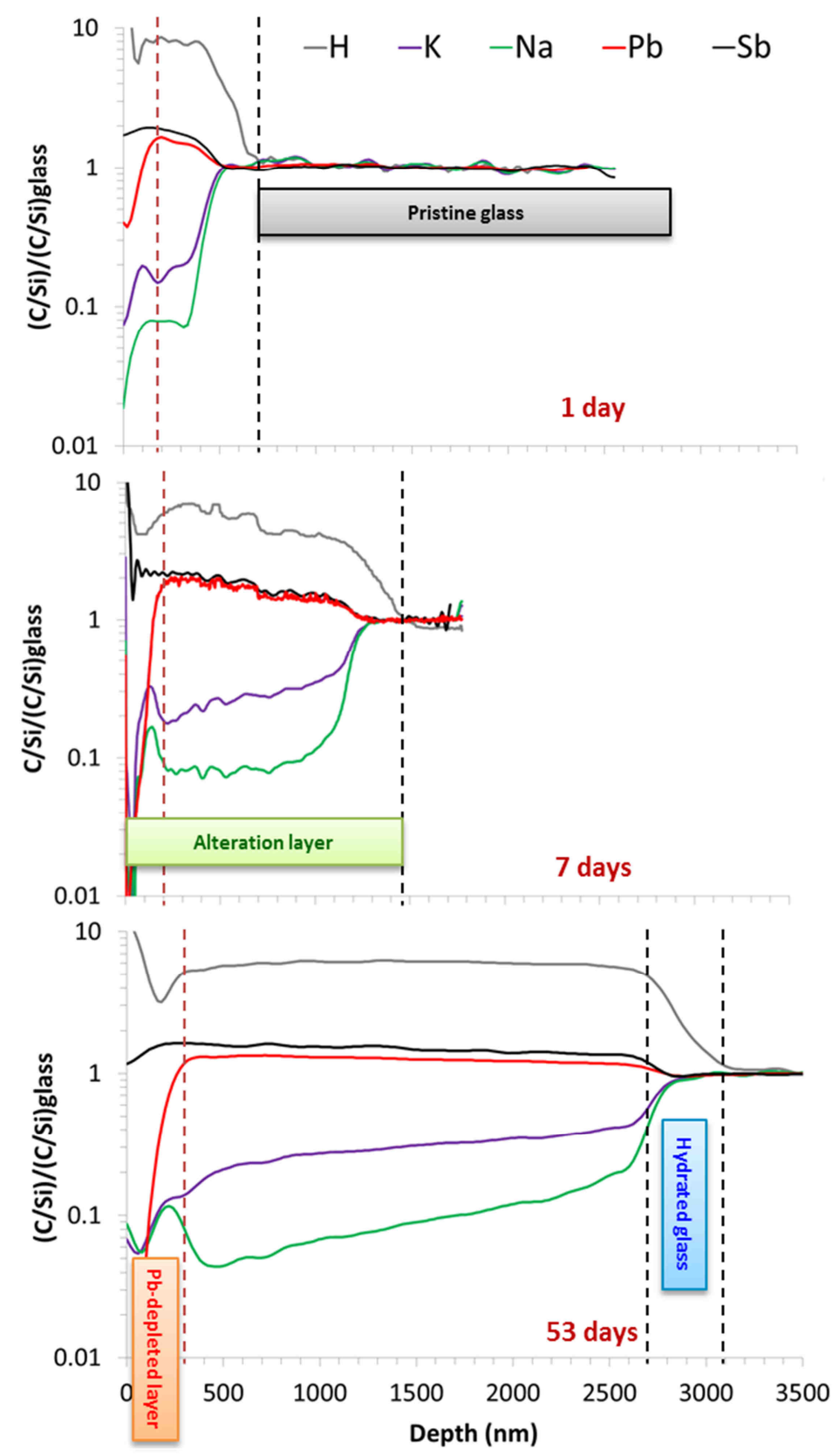

Figure 6. Elemental profiles obtained by ToF-SIMS on the glass altered at $70 \mathrm{C}$ for 1,7 and 53 days in acetic acid solution saturated with respect to amorphous silica. Data have been normalized compared to Si, which is the least soluble element. All the elements are thus normalized to 1 in the pristine glass; data lower than 1 indicate a depletion of the element, whereas data higher than 1 


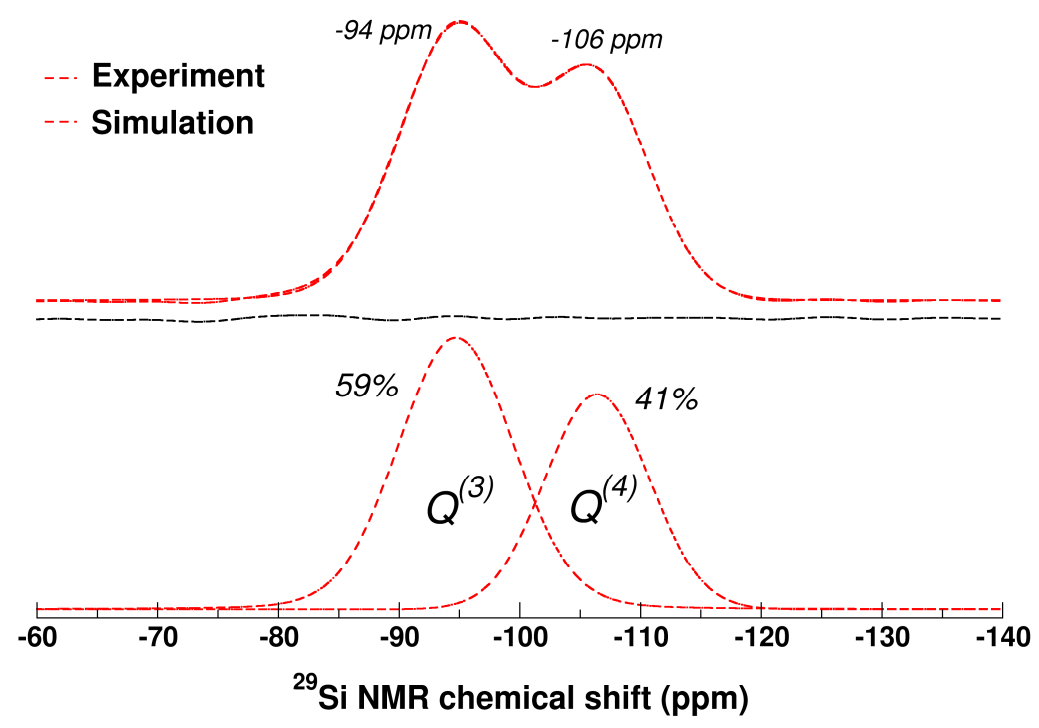

644

${ }^{29} \mathrm{Si}$ NMR chemical shift (ppm)

645

646

Figure S1. ${ }^{29}$ Si MAS NMR spectra of pristine glass (solid line) and simulated spectra (dotted lines)

647

648

649

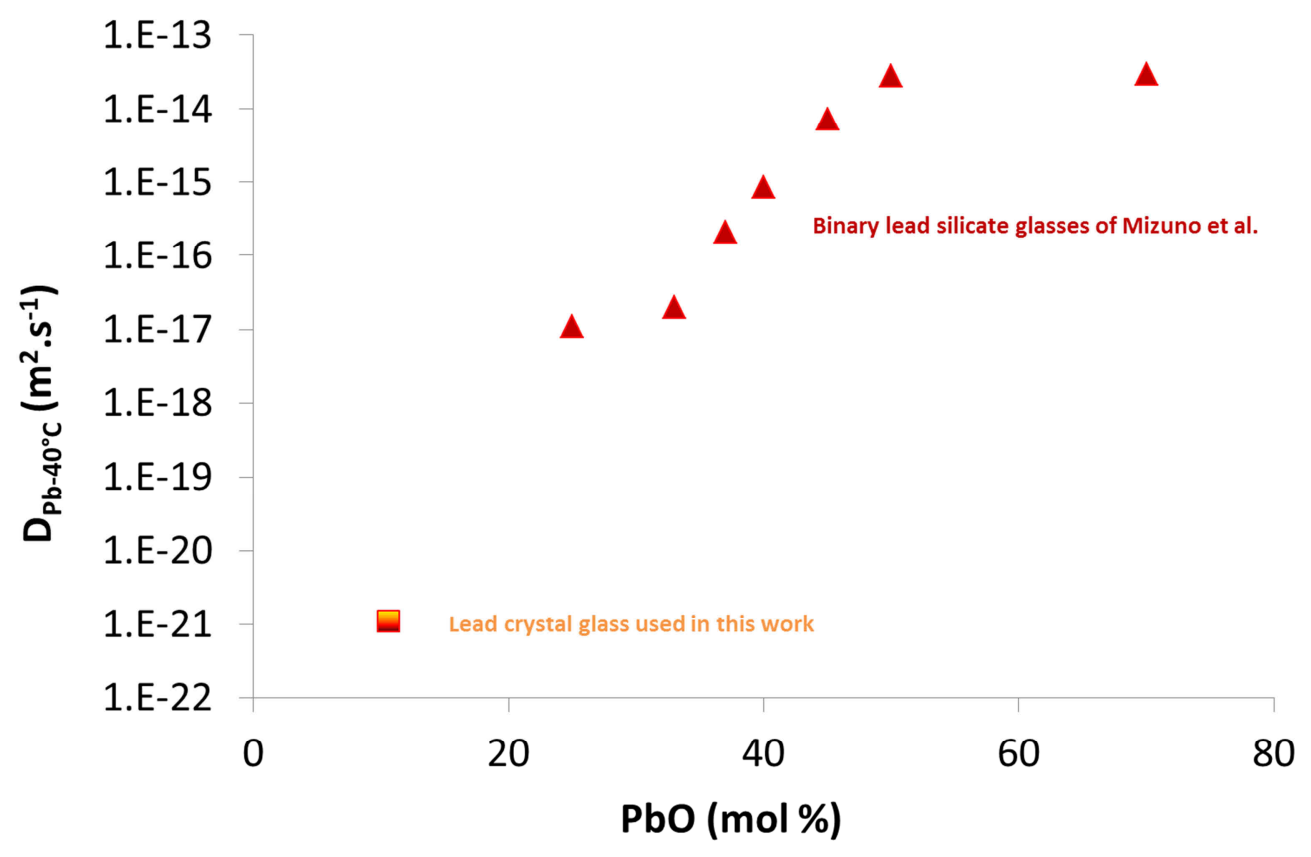

650

651 Figure S2. Comparison of diffusion coefficients measured at 40 C in the lead crystal glass used in this 652 work and in binary lead silicate glasses of Mizuno et al. ${ }^{10}$.

653

654 
(a)

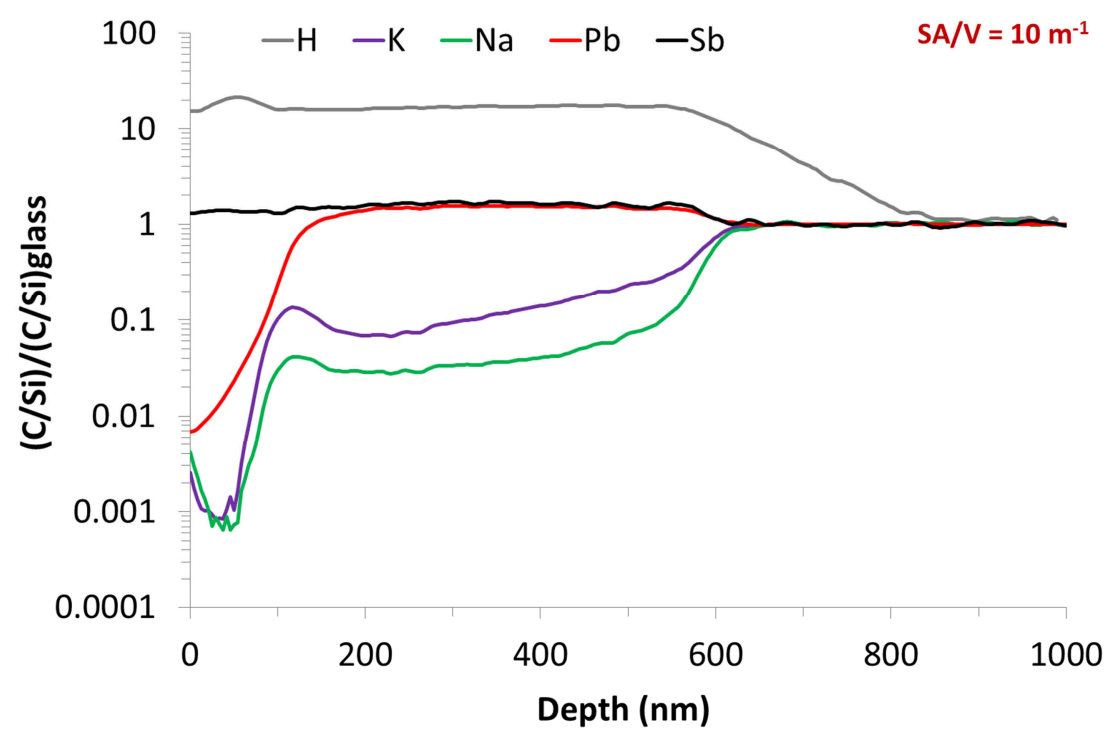

657 (b)

658

659

660

661

662

663

664

665

666

667

668

669

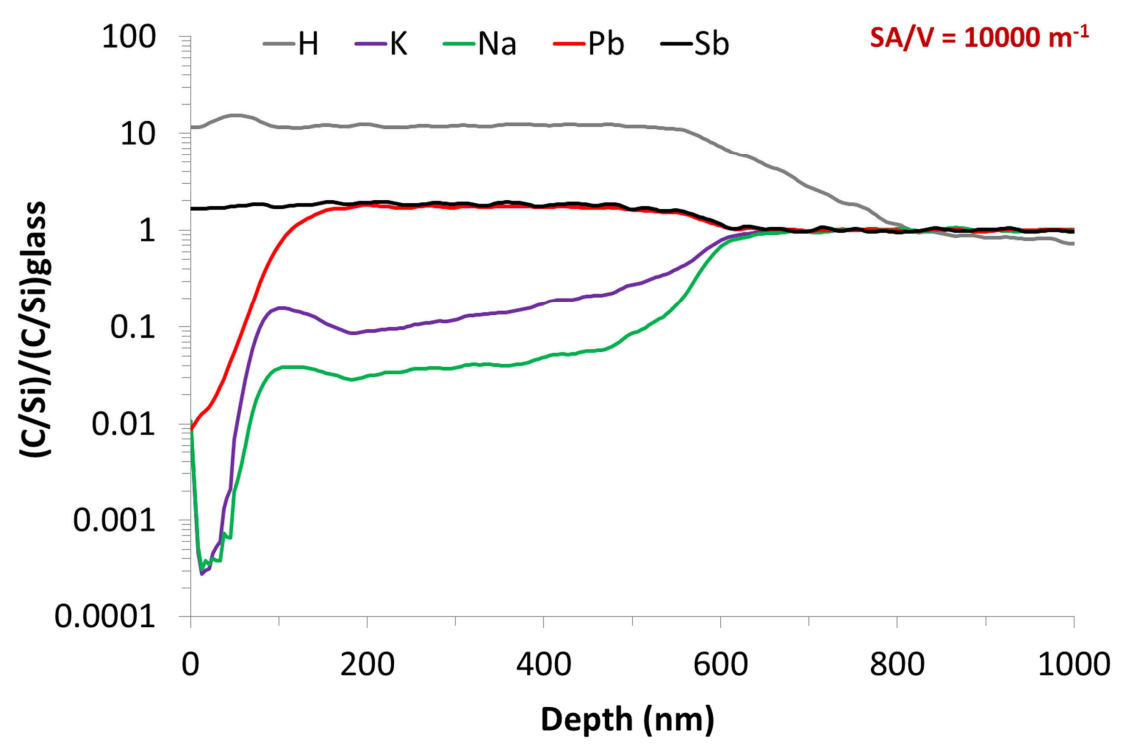

Figure S3. Elemental profiles obtained by ToF-SIMS on the glass altered at $22 \mathrm{C}$ for 1 year in acetic acid solution with $S A / V=10 \mathrm{~m}^{-1}$ (a) and $S A / V=10000 \mathrm{~m}^{-1}$ (b). Data have been normalized compared to $\mathrm{Si}$, which is the least soluble element. All the elements are thus normalized to 1 in the pristine glass; data lower than 1 indicate a depletion of the element, whereas data higher than 1 indicate an enrichment. 
(b)
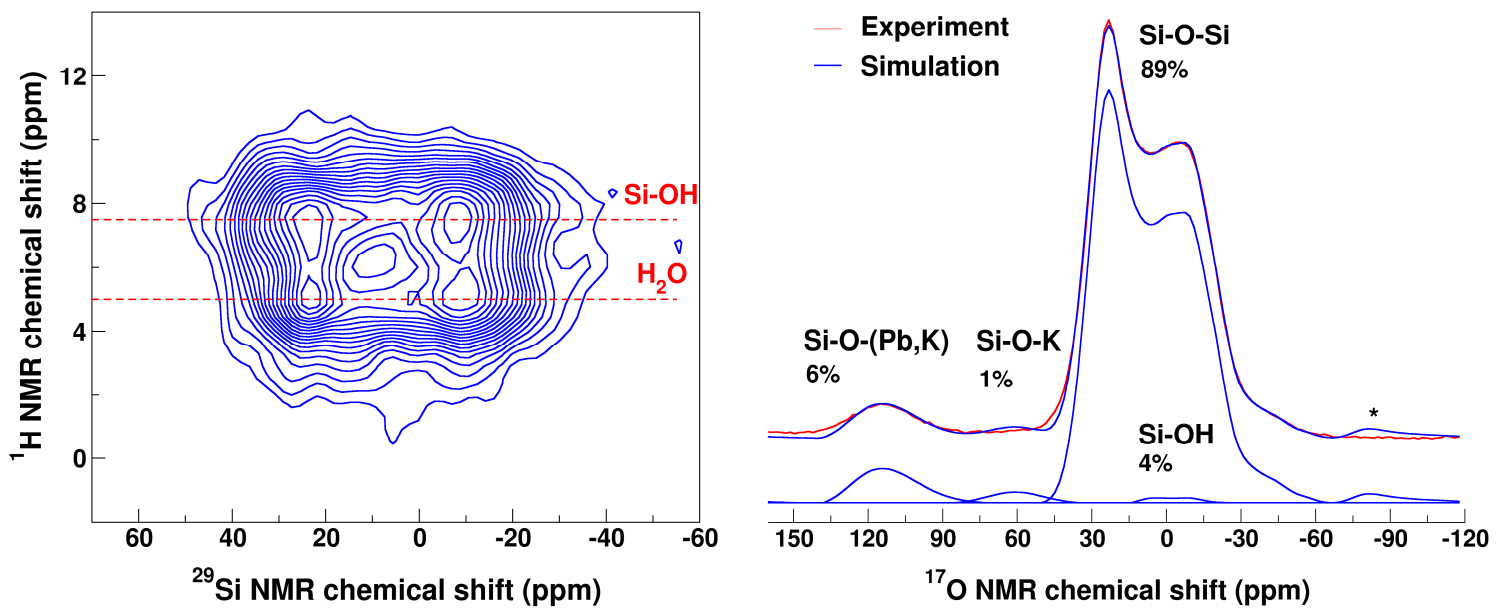

671

672

Figure S4. (a) ${ }^{1} \mathrm{H} \rightarrow{ }^{17} \mathrm{O}$ HETCOR spectra with $2 \mathrm{~ms}$ polarization time of altered glass.

674

(b) Simulation of the ${ }^{17} \mathrm{O}$ MAS NMR spectra of altered glass

675 (35 days at $70^{\circ} \mathrm{C}$ in acetic acid solution with oxyge $n-17$ enriched water).

676

677

678

679

680

681

682

683

684

685

686

687

688

689

690

691

692

693

694

695 

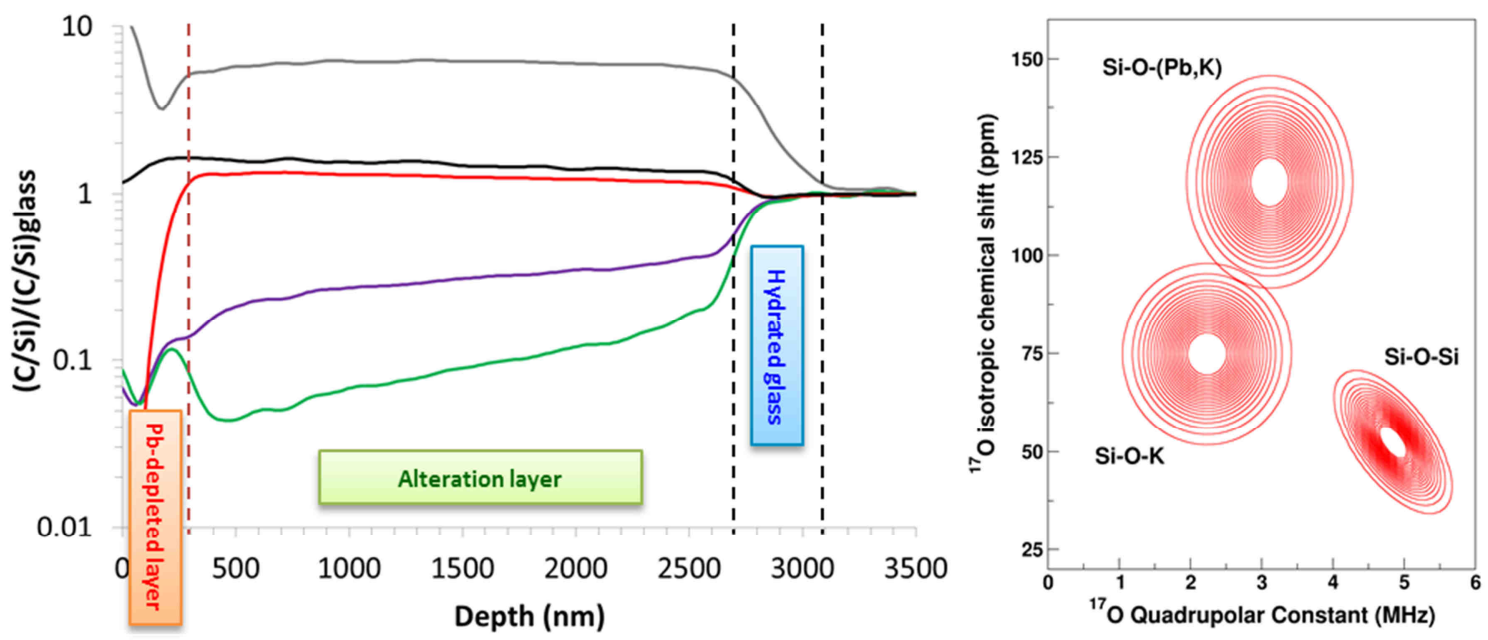